\title{
XXX. Memoir upon the compound and smooth or simple eyes of insects, and on the manner in which these two species of eyes concur in vision
}

\section{Marcel de Serres}

To cite this article: M. Marcel de Serres (1814) XXX. Memoir upon the compound and smooth or simple eyes of insects, and on the manner in which these two species of eyes concur in vision, Philosophical Magazine Series 1, 44:197, 183-191, DOI: $10.1080 / 14786441408637437$

To link to this article: http://dx.doi.org/10.1080/14786441408637437

曲 Published online: 27 Jul 2009.

Submit your article to this journal $[\pi$

山 Article views: 2

View related articles 


\section{Memoir upon the compound and simple Eyes of Insects. 183}

this question. Dr. Thomson, a respectable chemist, I believe, but (as har as his Sistory of the Royal Society, and his ill-judged intererence in this bunesa, (umish evidence) a man of very moderste mathematical and philosophicil attaimments, affirms that "the point can only be setted by repeating the observations." "The Chevalier Delambre the nost exeollent theoretical and practical astrongner now living, is of a different opinion, Whesher your scientific readers will concur in sentiment, on this purely astronomical inquiry, with the chemist or the astronomer, it is not ciblicult to predict.

When a writer has rentered himself notorious for assming an air and tone of superiority and infalibility in all his controversial productions, which ill accords with his palpable mediocrity of taient and linowierge; and when he is indiscreet enough to libel a whole class (and that class comprehending such nen as Archimedes and Newton and Laplace) for the supposed mistake or miscondact of an indiviual; it would neither be ungenerous nor unijust to lower his pretensions, and completely expose his numerous blunders. But it is a task which, however beneficial it might be to the public, and however easy of accomplishment, has no fascinations for me. Dr. Thomson's other observations*, therefore, not bearing upon the main question, I leave to sink by their own weight; and remain,

$$
\begin{aligned}
& \text { Sir, Yours respectfully, } \\
& \text { Royal Miltary Acaderny. Wolwich, } \\
& \text { September 6, 1814. }
\end{aligned}
$$

XXX. Memoir upon the compound and smooth or simple Eyes of Insects, and on the Manner in which these two Species of Eyes concur in Vision. By M. Marcel de Serres, Professor of the Sciences in the Imperial University.

[Continued from p. 118.]

I. HE tunic of the comea is generally black in the coleopterce: it is the same in those which want the choroid and the mucous varnish. The colour of this tunic is on the contrary much more variable among the orthoptera, and sometimes one and the same

\footnotetext{
* Such, for example, as the reasons he assigns, why the tirst two volumes of "The rrigommetrical Survev," which were actually printed and published in The Philosophical Praisactions, were not admitted juto that work. O exquisite plitosopher! to anuse and satisfy himself with accounting for the non-appearance of a phanomenon in a certain place, which did, notwithstanding, appear there permunently! should I ever again be involved in controversy, may I have the good fortune to meet with such another a)ponent!
} 
eye presents it of two diferent shates, as we see in the locusta lilifolia: lastly, in certain species the tunic of the coriea presents stripes variously coloured, and traced with the greatest regularity. These stripes are paralic in the grylus ineola : some are of a blackish brown, and others of a yellowing gray, the clear colour of which dips into that of the rest of the eye. It must be remarked, that frequently these shades are effaced after death, on account of the alterability of the twic of the comea. There are even species in which the tanic of the comen is as it were marbled; then it exhibits variots shades in diferent parts of the eye.

As to the tunic of the smooth or simple eres, it is seldom black in the orthopterce, and its colours are always uniform in the same eye; althongh they are much variegted, when we examine a great number of species. The nost common colours are white, red, or pale green.

A great number of hemiptore also present the tunic of their cornea of colours pretty much variegated; but its brown or rather black tints are mich more common than in the orthopterce. As we find among the latier, several licmipterce present the tunic of the cornea of their smooth eyes, either whitish or of the most agreeable red, as is observed in the common grasshopper. Lastly, it appears to me, that almost all the hemipterce which live in water have the tunic of their cornea completely black; perhaps it is the same with all the coleopterce which have the same way of living.

The lepidopterce furnished with the funest colours have also the tunic of the cornea of shades greatly variegated. Nevertheless, among all those which fiy at sunset or during the night only, we observe that the tunic of their comea is generally black. To conclude: the ease is the sane with several species of diumal butterflies: for instance, the potilio podalwins has the tanic of the cornea completely blach; and notwithsianding the sombre hne of this colour, the varnish of the chorod is very thich in this species. In the papilio atalania the tunic of the comea is of a clear brown; thas the black point resuling from the aperture through which the optic nerve passes, is seen on the outside of the eye. It must be observed, however, that as this circular aperture is formed in this species by vesicular trachex, and these trachew being a little separated from each other, the blaek point which is seen gencrally it the exterior of the eye, seems surrounded by other black points, which present a peculiar form, all having a smalier extent than the central point. In the papilio cardu, the tunic of the comea is of a briliant green, but much clearer in the lower part of the eye than in the upper, on account of the luminous rays less easily reaching them. 
them. This tmie is thin, wheres the varnish of the choroid and the chomid itself are on the contrary titick. We also observe externally on the eye the central black point, and several others produced by the same ceuse with those of the eve of the papilio atalunta. Only these blackish points are more irregular in their form than tho e of the proilio atalanite.

The larve of the icpid pietce have only smooth eyes situated generally on the sides, of the heut? They are varible in colour and number. Thus we obswe eight in the wlitworm, and six only in the eatervillar. The former are blaek, and the latter transparent. As to their interial structure, we shall speak of it elsewhere, inasmueh as it cxhibits some üfferences from that of the other sinooth eyes.

In the neuropterce, the turic of the cornea is also very much varied, and its colours vary much in various species. In the likellula vulgaris, the compound eves cxhibit all their upper portion of a redilish brown, and ail the lower of a yellowish green. On carefuly removing the correa, it is easily seen that the difference in the two colous is owing to the diversity of colour in the tunic of the cornea. It seems even that this tunic is thicker in the brown part of the eye than in the green. We shall also remark that the upper acess of the cornea are greater than the lower; which is rather singular. If we remove the cornea, we distinctly perceive the optic nerves passing through the choroid and its varnish, membianes which are easily distinguished from their being of a drep black.

The circular trachea surromols the retina, and its ramifications pierce with the optic nerves all the other membranes, dispersing thernselves ad infuitum under the cornea. This disposition is so evident, that we may easily conceive bow Swammerdam thought the cornea was formed by the meeting of these tracher. In other respects the eye of this libellala presents nothing particular, with the exception of the enlargement or great extent of the retina.

I have also dissected the eyes of certain larve of agrion and ceshma, but have observed nothing very different. These larva seemed to want the circular trachea, the place of which is supplied by an infinity of other trachea, which spread in a great number around the optic nerve, which is very broad and thick in these larvæ. I never observed that the eye had any particular conformation in the species which habitually frequent the water; and this remark is important, because the case is very different in the other animals. The form of the cornea also presents differences in the species in the aquatic insects, as well as in those which live habitually in the air. 
If the tunic of the cornea presents shades much varied in the lepidopterce and neurcpterce, these shades are not less varied in the hymenoptera, in which we sometimes see a giar, a green, a yellow, and even all the shajes of black. Certain bees, and particularly the violacer, present this tunic of the most opacyue black. Geuerally the hymenopierce have their cornea very thick, and it is not dificult to remove it by this slices. Sonetimes this cornea is surrounded by hairs, and rarely do they issue from the cornea itself. In a great number of species, the circular trachea is totally wanting; but its place is alwavs supplied by other and smaller trachex which surround the nptic nerve, and in general these trachexe are extremely multiplied.

What has been said with respect to the eyes of the hymenopterce is applicable to those of the diptere, which have the tunic of the cornea with the most variegated shades. In a certain number of species these shades are very brilliant, and the tabanus as well as the musca hold a distinguished part in this respect.

Certain species of syrphus present, at the exterior of the eye, two semi-circular stripes deeper than the general tint. These stripes are produced as usual by a deeper shade of the tunic of the cornea in this part of the eye: but what renders this disposition remarkable is, that there are numerous hairs precisely in this very part of the compound eye, and which originate from the cornea itself.

As to the eyes of the apterce, they are in general of dark colours, and not very large. These insects seem therefore not to be much favoured in respect to the organ of sight, and probably their way of life does not require acute vision.

I $t$ is remarkable that the insects which live in water have in general their eyes dim and opaque exterually, nearly like those which exist in dark places. Thus the nynuphs of the libellulce in passing to the condition of a perfect insect assume brilliant and transparent eves, whereas previous to their last metamorphosis these eyes were dull and without lustre. This observation has not escaped the sagacity of Reaumur in his History of Insects.

In the descriptions which we have given of the situation and form of the compound and simple eycs of insects, it will be remarked that the former disposition is less subject to vary than the latter. This contideration might have arisen a priori, since no form ran exhibit differences in any order of animals, without other variations following in the parts which surround those whose disposition changes. The only very remarkable example which we can mention of the variation in the position of the compound 
conpound eyes, is that of the diopsis ichneamonea. This insect exhibits is eyes situated nearly like those of the mollusci: thus they are placed at the extiemity of a long pedicle, or a kind of contractile tentacular point, but which can at least follow all the motions of the head. We may say, on observing this singular organization, that this ineect has its eyes at the extremity of a telescone; lut as we have not scen it alive, nor dissected it, it woud be diffentt to decide how far this idea is correct.

As to the descriptions which we shall presently gire of the relation which exists between the size of the bodies and that of the compound eyes, they prove that the lipterce, the liymenopterce, lepidopierce, and nfurcoterce have very large eyes: it even seems that there are $f_{2} w$ animals equaly favoured. As a great number of colentierce and hemipierce liave also rery large eyes in comparison to their bodies, we may say that this size is very general in all insects. The two solitury examples of the phasma and scolopendre onght not to prevent us from concluding that, of all the animals, inwects have the largest eyes in comparison with the size of their bodies.

\$.I. Of the simple or smooth Eyes. The number of simple eyes is far from being as constant as that of the compound eyes. Certain species present two; others four, six, and eight; but in general we observe three. 'This number is even pretty constant in families which have at once compound and smooth eyes. We rarely see exceptions to this arrangement; and the llatta, as well as certain acheta, are perhaps the only kinds which, having compound eyes, have only two sinple eyes situated on the upper part of the liead. When there are three simple eyes, they are always arranged in the form of a triangle, so that there are two Iateral, and one in the middle : their situation is also constantly on the summit of the head. Sometimes, however, the simple eyes are arranged two on the summit, and one in the middle of the front of the head. This arrangement holds in the gryllus, the triuxalis, the acrydium, the locusio, and the gryllotalpa.

The empusa, which have upon the summit of the head a small triangular elongation, cannot on account of this organisation see objects with their eye in the middle.

The general form of the simple eyes is very variable: it seems, however, that in general that of the lateral eyes is elongated and elliptical, whilst that of the middle one is round: there are also many exceptions in this respect, since the acheta and the gryliotalpa present that in the middle of a very much elongated oval of which the greatest diameter is transversal.

The smooth or simple eye is formed of an external hard transparent membrane, convex externally, and concave interially. This membrane enveloping the eye necessarily determines its 
form: it is not composed, like that of the componnd cyes, of an infinite number of faceta, but rather of a memlyme of a single piece, and on which no divisions me perceptible. We may consider this first membrane as a comea, on account of its transparency, a transparency which we ohserve even at the exterior of the eye, on account of the litcle colour of the varnish applied on the membranes situated under it.

After having removed the conca, wa find a visents tunic more or less thich, and of whin the eolour also undergoes considerable variations. Thus this tunic or mamish presents the most opposite culours: it is almost always black in the hymenopterce, whereas it is whitish in the orthopierco. In the cateryillar, this varnish is frequently black, yellow, or red, and sometimes it is of the most beautful brilliait green. This riscons tunic has been regarded by Swanmerdam as a kind of uvea, altiongh it seems very like the tunie which covers the conea in compround eves.

We ought not, however, to decide that the tunic of the cornea of the simple eyes is distinct from the varnish of the choroid. This appears probable notwithstanding, since in certain species the external colour of the simple eyes is not the same with that of the varnish with which the choroid is covered. Thus much is certain, that the cornes of the simple eyes is always coated internally with a kind of varuish, the colour of which appears at the exterior of the eye on aecount of the transparency of the comea. This coating surrounds the optie nerve, which proceeds into the concavity of the cornea after having pessed through the choroid and its varnish. Swammerdam very properly remarks, that the swooth eyes of insects receive nerves which are furnished to them by the cerebriform ganglion lodged in the head. Lyonnet, whose researches announce so much sagacity, has also observed that the simple eves of the willow caterpillar are composed of a cornea and a choroid traversed by the extremity of the optic nerve".

The optic nerves of the simple eyes issue immediately from the brain, when these eyes are removed far euongh from each othe: ; but when, on the contrary, they are elose together, as observed in the caterpillar and a great number of larvæ, the sptie nerves are only drsisions of a larger nerve which issues directly from the brais.

Lyomet has described this arrangement accurately, and the figure which he gives of it, Plate XVIII. No. 6 , is very correct. Then there exists a peculiar membrane in the form of a funnel, to which the six branches of the optic nerve are attached, and

* Thite Atcatomigue de la Chenille du Siule, par Iaronstef, p. 570. 
this membrane ends at the place where the nerve iself divides into these six branches. We do not know pesitively, if this arrangement cxists in the spiders: we only kuow that it does not hold in the scorpions. Besides, externally the eycs of the spiders and of the scorpions bave the sane structure and figure with the simple eyes of insects.

Immediately after the optic nerve and the tunic of the corres, we observe a peculiar menbrane which we shall consider as is kind of choroid. It exhibits, however, this difference from the choroid of the comronnd eres, that it has no vaminh so distinet; and finally, its breadth is alwavs greater than the circumference of the conea itself. This meribrane, coloured fiecuently in red or black, is also conetimes colourless; and lastly, its whiteness is so dull that it is easy to distinguish it from the tracheæ. The thickness of this menibrane is great enough to make it resist even a long maceration.

In the species in which the simple eyes are whitish, we see this membrane clothed with a coating of colsurs varying with the colours of the tunic which covers the choroid. This arrangement is even very perceptible at the exterior of the eje.

It would seem that this choroid is particularly very thick and white in such species as have their cornca concave and as if sunk. This arrangement must have taken place on account of the divergency undergone by the rays of light in arriving on a concuse and transparent surfice, their direction even being parallel, a divergency which is such that we may very well conceive that the eye would he too much affected by it, if a black menbrane had also absorbed a certain number of lumiuous rays. A white nrembrane, sending back on the contrary all the rays which it receires, may augment the excitalility of the optic nerve, and thus contribue to render the vision more distinct. Although this species of choroid presents in certain circumstances a very great whiteness, it is nevertheless always easy to distinguisit it from the trachca, the only vessels with which it can be confounded. For, as little as we are in the habit of seeing the organs of insects, we can casily ascertain the trachex from their azure colour; and besides, by dissecting them in water (the most advantageous way of acting in these experiments) we see the trachere rise above the surface of the liquid; and from that moment we can no longer have the smallest doubt, for the trachese are the only organs which have so little specific gravity.

This choroid, the membranes of which are close and very thick, seems formed by a cellular texture of rery cluse meshes, over which a heap of trachex are distributed. It is therefore underneath the cornea that the optic nerve is situated, which issuing from the anterior faces of the brain proceeds to the mid- 


\section{Memoir upon the compound and simple Eyes of Insects.}

dle of the eve. It does not appear that this optic nerve has any swelling at its base, or that a kind of retina is formed analogous to that of the compound eyes. In some species it appears to me that this nerve becomes broader towards its extremity, i.e. at the point where it corresponds to the cornea. I shall not, however, assert this positively, for it is possible that this dilatation may depend on the contraction produced by the section of the nerve. As I have not dissected these organs in the living subject, (which ought always to be done for the sake of precision,) I have not been able to verify, whether this dilatation depended on the sensilility of the nervous organ. However the case may be, the optic nerve before reaching the cornea traverses the muscles of the various parts of the head, sometimes enters a trachea, penetrates afterwards throngh the choroid and its varnish, and afterwards, when surrounded with the tunic of the cornea, corresponds to the internal surface of this membrane, on which it seems to lose itself.

As the cornea of the simple eyes is not, like that of the compound eyes, divided by numerous facets, it has not been necessary that the small nerves should give it a great number of small threads, but only that they should proceed to the point where the divergency of the rays of light should be the least considerable.

The small optic nerves which proceed to the simple eyes issue from the brain. As their position varies in regard to the other parts, they are sometimes the second, third, fourth, or fifth pair of nerves: this depends on their situation with respect to the various organs of the head, a situation which determines by what pair they are furnished. These nerves are directed always towards the simple eyes, being retained in their position either by pneumatic pouches, or by trachex, proceeding more or less obliquely according to their position with respect to the brain. They always terminate under the cornea, forming a kind of retina.

It results from this description, that the simple eyes are formed quite differently from the compound eyes. Thus the cornea of the former is all of one piece, whereas in the latter it is formed by the union of a great number of hexagonal facets. As to the tunic of the cornea, it does not exhibit any difference in the two kinds of eyes, except perhaps in point of thickness; but with respect to the varnish of the choroid, it is always less distiuct in the simple than in the compound eyes. Finally, the choroid is not always black in the simple eves, whereas it is miformly in the compound. Sometimes this membrane, instead of being black and opaque, is of a peculiar whiteness and lustre To conclude: this membrane and its tunic are placed in the same way with respect to the other parts in both kinds of eyes, and their 
uses are also similar. The large circular trachea, which we observe in the compound eyes when they present a choroid, does not seem to exist in the simple eyes. In fuct, the trachea or pneumatic pouches which belong to them are used in supporting the optic nerve, and perhaps al oo in forming a part of the choroid in that sort of eye. At least the trachee of insects seem to perform the functions of the blovd-vessels which are observed on the choroid of the red-blooded animals.

[io lie cuntinued.]

XXXI. Some Particulars respecting Hail Storms in the West Indies in the Month of April 1814; and Experiments to ascertain the medicinal Powers of the Hura crepitans.

\section{To Mr. Tilloch.}

Sin,-Though I have already communicated to Sir Joseph Banks some particulars respecting the late hail storms in this island and Saint Christopher's, a slight notice of their uncommon phænomena may not be deemed altogether undeserving of a place in your Magazine.

The fall of hail intermingled with masses of ice took place in the island of Saint Christopher's at eleven o'clock in the forenoon of Weduesday the 13th of last April, at which time I was absent from that island on a visit to a friend here. The weather had been for some time previous excassively dry, and the heat in general very great; and even upon the morning of the day on which this phrnomenon appeared, the atnosphere was at an early hour close, sultry, and oppressive. As the day advanced, black and dense clonds gathered from all sides, and thunder was heard at a distance; a small quantity of rain fell in the southern and western parts of this island (Nevis), but the thickest part of the storm skirting our northern shores proceeded along the Salt Pond Hills towards the valley of Basseterre (St. Kitts), where an abundance of rain fell. A short time before the hail fell, an rnuknal and, as some fescribed it, even painitul sensation of cold was observed, a loud clap of thunder was heard in the south-east, and the rattling of the hail upon the roofs of the houses attracted the attention of the inhabitants little acquainted with the nature of such appearances.

The fall of hail was by no means general throughout the island, confuing itself to certain narrow limits little removed from the line of mountains which, after the manner of the Appenines, traverses the centre of the island from east to west. No hail fell at Basseterre; but at the estate colled O'Gee, be- 